\title{
Parotid Branchial Cyst: A Case Report
}

\author{
Authors \\ Dr Santosh Thorat ${ }^{1}$, Dr V.S.Dube ${ }^{2}$ \\ ${ }^{1}$ MBBS MS FIAGES, Asst. Prof Surgery, ${ }^{2}$ MBBS MS, Professor General Surgery \\ Dept. of General Surgery, B J GMC \& Sassoon Hospital Pune
}

\begin{abstract}
Lymphoepithelial cyst or branchial cyst is an aberrant pathology during embryogenesis involving the branchial Arches. The usual site of presentation is below the angle of the mandible in the anterior triangle of the neck.

Branchial cyst masquerading as a swelling in the parotid region is of uncommon occurrence and there are only about 100 reported cases.

Here we report a case of 28 year female presenting with a 6 month history of painless cystic swelling in the region of the parotid, for which total excision of the swelling was done followed by histopahological examination which revealed it to be branchial cyst.

Due to rarity of this pathology and unusual presentation authors are reporting this one.

Keywords: branchial cyst, lymphoepithelial cyst.
\end{abstract}

\section{INTRODUCTION}

Cystic lesions within the parotid gland are uncommon comprising approximately $5 \%$ of all salivary gland tumours; many of them represent components of cystic neoplasm ${ }^{1}$. The Branchial cyst or lymphoepithelial cyst are the lesion found behind the angle of mandible in the anterior triangle of neck at the junction of upper third and lower two-thirds of sternocleidomastoid muscle. These cysts have the lining of stratified squamous epithelium resting on a complete or incomplete band of lymphoid tissue with part of cyst wall resembling lymph node ${ }^{2}$. They may also rarely occur in parotid gland ${ }^{3}$.

We are reporting an case of branchial cyst or lymphoepithelial cyst in parotid gland region. The swelling are difficult to diagnose preoperatively even with investigation. The swelling was excised in Toto without any damage to the facial nerve or parotid and its structure and the final diagnosis is established by histopahological examination.

\section{CASE REPORT}

A 28 years old lady with a swelling in left parotid area was referred Deptt. of General Surgery. She noticed this swelling around 6 months ago. The swelling was not associated with any history of pain, fever, or any discharge in its whole course. It has started to increase in size gradually from last 6 months. History of previous trauma or upper respiratory tract infection or any thyroid enlargement was absent. Her routine medical examination was found to be unremarkable. 


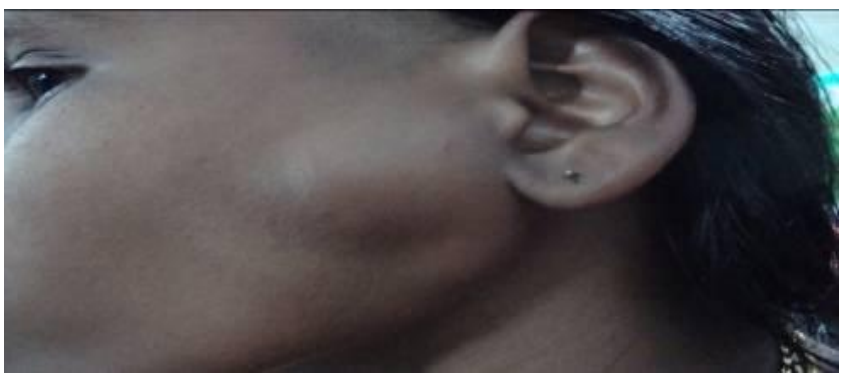

On examination; a diffuse soft fluctuant swelling of size $3 \times 3 \mathrm{~cm}$ was found in pre auricular region. The overlying skin noted to be normal and freely movable over swelling. Examination of facial nerve was within normal limits.

There was no associated regional lymphadenopathy. Intra oral finding revealed a free flow of saliva from left parotid opening (stensen's duct).Bidigital examination revealed no enlargement of deep lobe of parotid gland.

Ultrasound was hypo echoic lesion with posterior enhancement suggestive of cystic swelling. Further investigation in the form of FNAC from the swelling was done. The aspirate was a thick cheesy whitish material, which was subjected to the cytological evaluation. The report of the FNAC was suggestive of branchial cyst or lymphoepithelial cyst with no any atypical cells.

Findings were explained to the patient with advice of surgical excision. lazy's' incision in front of auricle was given, this incision will help to minimise post-operative scarring. The incision was explored layer by layer until it exposed the well encapsulated cyst underneath it. The cyst was free of any connection with the parotid gland or the facial nerve and was excised completely. The specimen was sent for histopathological examination.

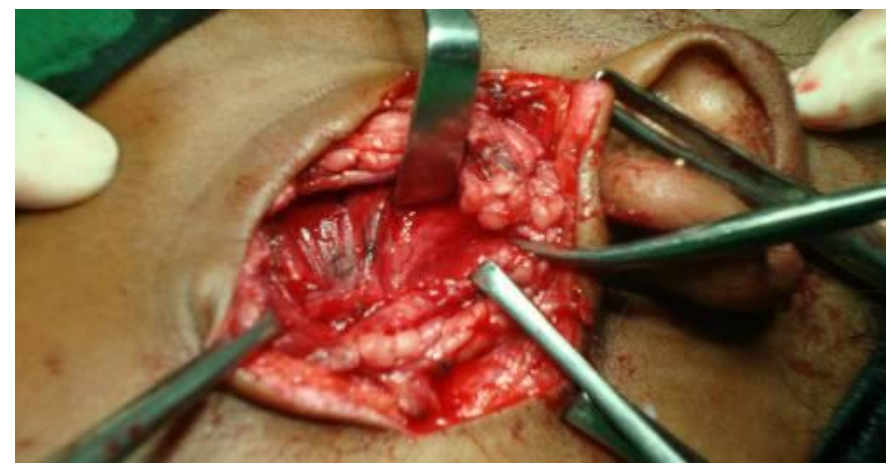

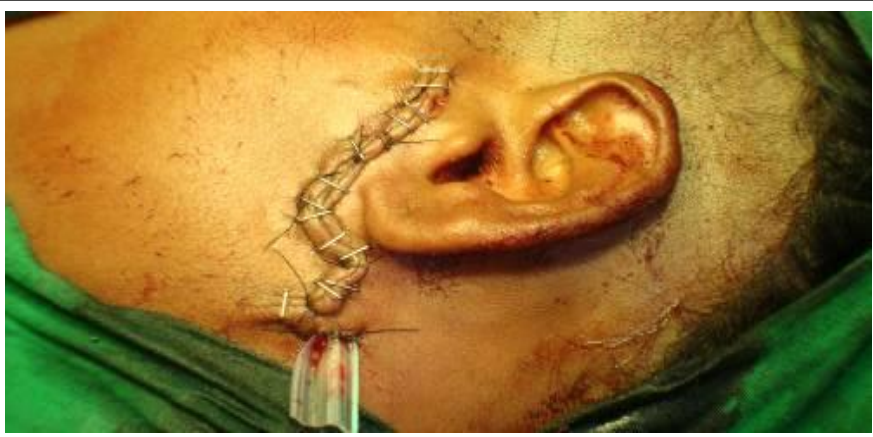

The operative area was drained with PVC corrugated rubber drain. The closure of the wound done with 4-0 polyglactin and skin is closed with stapler. On $3^{\text {rd }}$ post operative day she was discharged and follow up at one week duration, there was no any evidence of post op wound infection or facial nerve palsy. The patient is doing well till date.

Histopathological examination report confirmed the lymphoepithelial cyst however no nuclear atypia was reported.

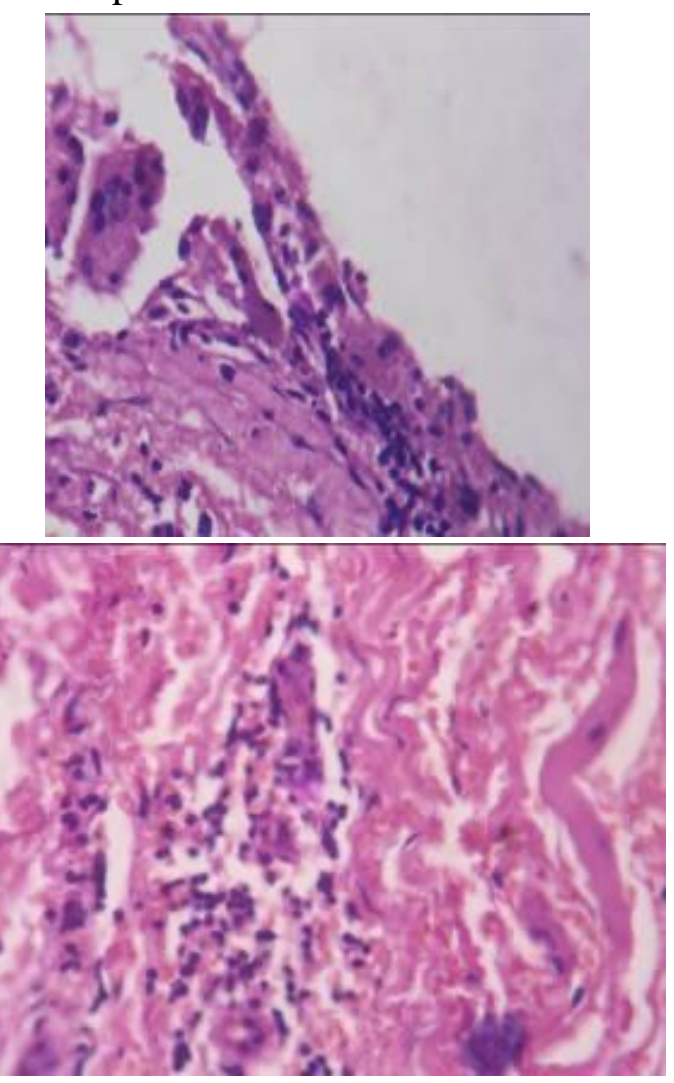

\section{DISCUSSION}

Lymphoepithelial cysts so called "branchial cysts" within the parotid gland are rare.

The first reported case of branchial cyst in parotid gland was given by HINDERBRAN in 1895, since 70 cases Of this type of cyst have been 
reported $^{9}$. Another 33 cases was found by fujibayashi through the review of 5 publications in concern with branchial cyst or the parotid disease $^{3}$.

The location of the cyst in this present case was uncommon. These cysts have equal distributions among males and females with painless swelling in parotid region without any attachment to facial nerve ${ }^{4}$.

Aetiology of these cysts is controversial with several theories proposed such as-

$>$ Classic branchial cleft theory ${ }^{5}$.

$>$ Thymo-pharengeal duct theory ${ }^{6}$.

$>$ The inclusion theory ${ }^{7}$.

However for this present case the inclusion theory or so called recent theory seems to be the most feasible explanation for the lymphoepithelial cyst found in the parotid gland. This theory considers origin of these lesions due the cystic changes in parotid gland epithelium that becomes entrapped in upper cervical lymph node during embryonic life.

The most common sites of lymphoepithelial cysts were in lateral cervical area in review of 468 cases of branchial cysts from the files of Armed forces institute of pathology only 5 cases were located in parotid area ${ }^{7}$.

Now a day the parotid lymphoepithelial cysts are reported in increasing numbers in AIDS infected patients and are probably related to intraparotid lymphadenopathy associated with AIDS infection $^{8}$.

The ultrasound and FNA was found to be vital importance in pre-operative diagnosis and histopathological examination confirmed the findings of branchial cyst.

The histological picture in present case was in accordance with that of lymphoepithelial cyst; where epithelium lined cysts are seen in the lymph nodes, adjacent to or embedded in major salivary gland $^{10}$.

In the present case the cyst was well encapsulated and after complete surgical excision, no recurrence was reported.
Among the different theories; inclusion theory is the most feasible explanation for the present case. Golledge and Ellis ${ }^{11}$ defined these cysts according to two parameters; position and histology. With regards its position, the lesion must lie outside the midline of the neck or within any position in lateral aspect of the neck. With regards histology the cyst lining is squamous or columnar and is surrounded by lymphoid tissue.

As per the age of presentation- Telander and Deane $^{12}$ found in their survey that sinuses and fistulas typically arises in the first of the life and to a lesser extend in second decade; whereas cysts occurs in the adolescent and adults; as seen in the present case scenario.

There is no any specific sex predilection as per most of the observers ${ }^{13}$ but some researchers have noted that cyst appears more commonly in males than in females ${ }^{12,13}$.

Branchial cleft cysts may have the ability to becomes malignant ${ }^{14-16}$. To date, though there has been no report of such an occurrence. Because of their lymphoid nature; these cysts can be confused with a metastatic LN or a primary malignancy of thyroid gland $^{14-16}$.

Regardless of possible theories of origin, anatomical location and histological findings as discussed earlier; many authors suggested total excision of these cysts is necessary to prevent infection and sinus formation ${ }^{17}$.

However if the preoperative diagnosis is in doubt then superficial parotidectomy is an alternative ${ }^{18}$.

\section{REFERANCES}

1. Altman and Bailey,1994. parotid cyst a case report INT J Oral maxillofac. SURG23-165-166

2. Howie AJ; Proops DW 1982-7 5157.clinical otolargol the definition of branchial cysts;sinus and fistulae.

3. Fujibashi and Itoh; 1981 Lymphoepithelial cyst within parotid gland; a case report and review of the literature Int J Oral SURG 10 283-292-294. 
4. Antonisadis etal 1990-benign cyst of parotid gland Int J Oral maxillofac SURG19,139-140.

5. Rickles NH and Little JW (1967). The histogenesis of branchial cyst 2. A study of the lining epithelium Am J Pathol,50;765773.

6. Thymopharengeal Duct theory Wenglosswiki, 1913.

7. Bhaskar SN and Bernier JL (1959)Histogenesis of branchial cysts-a case report of 468 cases AM J Pathol 35; 139140.

8. Mandel L and Reich R (1992)-HIV related gland lymphoepithelial cysts -Oral Surg MED Oral Pathol 74 533-534

9. Camilleri AC and Lylod RE (1990)Lymphoepithelial cysts of the parotid gland.BR J Oral Maxillofac SURG 28,329-332

10. Elliott JN and Oertel YC(1990)Lymphoepithelial cysts and salivary gland AM J CLI Pathol 93;39-43

11. Golledge $\mathrm{J}$ and Ellis $\mathrm{H}$; The aetiology of lateral cervical cyst (branchial) cysts; past and present theories $\mathrm{J}$ Laryngol otol 1994.108;653-659.

12. Telander RL; Deane SA, Thyroglossal and Branchial cleft cysts and sinuses. SURG CLI North AM 1977-57;779-97.

13. Van de Mark TB; Weinberg S; Weizel H ;Branchial cleft cysts; a review and case report. Oral surg med oral pathol.1969, 38, 149-55.

14. Longhorn CF; solitary cystic nodal metastasis occult papillary carcinoma of the thyroid mimicking a branchial cyst; a potential pitfall (comment) clinical radiol.1994;49; 359-360.

15. Ahuja A; Ng CF; King W; Meterweli C; solitary cystic nodal metastasis from occult papillary carcinoma of the thyroid mimicking a branchial cyst: potential pitfall, clin radiol 1998;53;61-3.
16. Foss RD; Warnock GR; Clark WB; Graham SJ; Morton AL; Yunan ES; Malignant cyst of lateral aspect of the neck-branchial cleft carcinoma or metastasis? Oral surg oral med oral pathol.1991;71(2) 214-217

17. Maynard JD (1988) Solitary cyst of the parotid.Br.J.Surg 75(10); 1043.

18. Wymen etal,1988; Lymphoepithelial branchial cysts within the parotid gland Br.J.Surg 75(8) 818-819. 